\title{
ARE ALL TYPES OF MORALITY COMPROMISED IN PSYCHOPATHY?
}

Andrea L. Glenn, MA, Ravi Iyer, MA, Jesse Graham, MA, Spassena Koleva, MA, and Jonathan Haidt, PhD

\begin{abstract}
A long-standing puzzle for moral philosophers and psychologists alike is the concept of psychopathy, a personality disorder marked by tendencies to defy moral norms despite cognitive knowledge about right and wrong. Previously, discussions of the moral deficits of psychopathy have focused on willingness to harm and cheat others as well as reasoning about rule-based transgressions. Yet recent research in moral psychology has begun to more clearly define the domains of morality, encompassing issues of harm, fairness, loyalty, authority, and spiritual purity. Clinical descriptions and theories of psychopathy suggest that deficits may exist primarily in the areas of harm and fairness, although quantitative evidence is scarce. Within a broad sample of participants, we found that scores on a measure of psychopathy predicted sharply lower scores on the harm and fairness subscales of a measure of moral concern, but showed no relationship with authority, and very small relationships with ingroup and purity. On a measure of willingness to violate moral standards for money, psychopathy scores predicted greater willingness to violate moral concerns of any type. Results are further explored via potential mediators and analyses of the two factors of psychopathy.
\end{abstract}

Psychopathy is a clinical construct defined as a constellation of personality and behavioral features, including callousness; manipulativeness; a lack of guilt, remorse, and empathy; impulsiveness; sensation-seeking; and frequent antisocial and immoral behavior (Cleckley, 1976; Hare, 2003). Previous descriptions of the relationship between psychopathy and morality have used general terms such as moral insanity and without conscience (Hare, 1999; Pritchard, 1835), or have focused on a few aspects of morality such as the willingness to harm and cheat others (e.g., Blair et al., 2002; Levenston, Patrick, Bradley, \& Lang, 2000) or the ability to distinguish between moral and conventional transgressions. In a recent review, Blair (2007) has suggested that psychopathy is primarily associ-

From University of Pennsylvania (A. L. G.); University of Southern California (R. I.); University of Virginia, Charlottesville (J. G., J. H.); and University of California Irvine (S. K.).

Address correspondence to Andrea L. Glenn, 3720 Walnut St., Philadelphia, PA 19104; E-mail: aglenn@sas.upenn.edu 
ated with compromised care-based morality, or a lack of concern for the well-being of others. He suggests that other types of morality (e.g., disgustbased morality and reasoning about conventional transgressions) are likely intact in psychopaths. Recent work in moral psychology (Haidt \& Graham, 2007) has begun to more clearly define the different types of morality that exist universally, allowing us to test this hypothesis in a single study; these domains of human morality encompass concepts of harm, fairness, group loyalty, respect for authority, and purity. These five "moral foundations" represent our basic moral intuitions in the social world. This study is the first to simultaneously explore whether psychopathy is associated with deficits in all of these distinct moral domains.

Several taxometric studies indicate that psychopathy is a dimensional construct rather than a qualitatively distinct category of behavior (psychopath; Edens, Marcus, Lilienfeld, \& Poythress, 2006; Hare, 2003). Given the strength of the dimensional perspective, community studies on psychopathy are increasing (Lilienfeld \& Fowler, 2006). Findings from studies of community samples often mirror those observed in forensic populations (e.g., Benning, Patrick, \& Iacono, 2005; Lynam, Whiteside, \& Jones, 1999), indicating that there are continuities between community and incarcerated participants in the mechanisms underlying psychopathy. Thus, the examination of individual variation in degree of psychopathic traits within the general population can be beneficial in furthering our understanding of psychopathy. By assessing individual variation in psychopathy in a large sample, the present study aims to explore the relationship between psychopathic traits and different types of morality.

Prior studies of the morality of psychopathy have focused on issues of justice (Kohlberg, 1969) and the distinction between harmful and conventional transgressions (Turiel, 1983). Several researchers in the justicefocused Kohlbergian tradition have hypothesized that psychopathy may represent a lower stage of moral development, but empirical results have been mixed. In a study using Turiel's moral-conventional task, Blair (1995) found that incarcerated psychopaths do not distinguish between transgressions that have harmful consequences for others, which he labels moral transgressions, and conventional transgressions, which violate social norms or rules. Blair (2007) suggests that psychopaths may have deficits specifically in moral judgments involving harm to others; they do not appear to have difficulty in detecting or rating conventional transgressions, which resemble authority-based morality, as conceived by Haidt and Graham (2007). Furthermore results regarding disgust processing in psychopaths, which may underlie disgust-based morality, have been mixed (Blair, 2007). Blair (2007) suggests that the specificity of the moral impairment to harm-based morality may result from dysfunction of key brain regions, namely the amygdala and ventromedial prefrontal cortex. The amygdala is thought to be involved in learning to associate one's own harmful actions with cues of a victim's distress. Indeed, psychopaths demonstrate reduced autonomic nervous system responding to cues of dis- 
tress in others (Aniskiewicz, 1979; Blair, 1999; Blair, Jones, Clark, \& Smith, 1997), a lack of startle responding when primed with victim scenes (Levenston et al., 2000), and a failure to identify sad and fearful facial and vocal cues (Blair, Colledge, Murray, \& Mitchell, 2001; Blair et al., 2002), all of which have been associated with amygdala impairment. The ventromedial prefrontal cortex is involved in representing reinforcement outcomes, which when dysfunctional, may impair appropriate decision-making. Blair suggests that reasoning about conventional transgressions or disgust-based morality likely involve regions such as the insula and ventrolateral prefrontal cortex, which have not generally been found to be impaired in psychopathic individuals. In the current study, we seek to test the hypothesis put forth by Blair (2007) that psychopathy is primarily associated with impaired harm-based moral reasoning.

Haidt and Graham (2007) have proposed that morality can be understood in terms of five underlying psychological systems, or moral foundations. These five foundations are:

(1) Harm/care-representing concerns about violence and the suffering of others, including compassion and care;

(2) Fairness/reciprocity-representing the norms of reciprocal relations, equality, rights and justice;

(3) Ingroup/loyalty-covering moral obligations related to group membership, such as loyalty, betrayal, and expectations of preferential treatment for ingroup members relative to outgroup members;

(4) Authority/respect-representing moral obligations related to hierarchical relations, such as obedience, duty, respect for superiors, and protection of subordinates;

(5) Purity/sanctity - representing the moral ideal of living in an elevated, noble, and less carnal way, based on intuitions about divinity, feelings of moral disgust, and purity of body, mind and soul.

Several large empirical investigations with diverse samples have supported the existence of these five distinct moral foundations (Graham, Haidt, \& Nosek, 2009; Graham, Nosek, \& Haidt, 2009; Haidt \& Graham, 2007). A variety of methods and measures have been used to gauge foundation-related concerns, and confirmatory factor analysis models of the different measures have shown that five-factor models improve upon one-, two-, and three-factor models, weighing both fit and parsimony (see supplement to Graham, Haidt, \& Nosek, 2009, and Graham, Nosek, Haidt, Iyer, et al., 2009).

The first goal of the present study was to assess the relationships between psychopathic traits and each of these foundations of morality. While the evidence is quite strong that psychopathic individuals exhibit reduced concern about harming others (Blair et al., 2002; Levenston et al., 2000), less is known about the relationship between psychopathy and the other foundations of morality. Cleckley's (1976) portraits of psychopaths who betray their families, lovers, and bosses, and who have loose or no sexual morals, seems to suggest that we might find a reduction in concerns about Ingroup, Authority, and Purity as well as Harm and Fairness. However, 
Blair (1995) has found evidence of intact rule- or authority-based moral reasoning and evidence regarding disgust processing in psychopaths has been mixed.

Two main questionnaires were used to assess these relationships. The Moral Foundations Questionnaire (Graham, Nosek, Haidt, Iyer, et al., 2009) uses abstract relevance assessments and more contextualized moral judgments to measure individual reliance on each of the foundations. The Moral Foundations Sacredness Scale (Graham, Haidt, \& Nosek, 2009) assesses how "sacred" individuals find each of the domains by asking how much money it would take for them to commit an act that violates principles of the domain.

A second goal of the study was to explore potential mediators of relationships between psychopathy and the moral foundations. A measure of empathy was included based on the hypothesis that individual differences in empathy may mediate any observed relationships between psychopathy and the Harm and Fairness foundations. Similarly, a measure of Social Dominance Orientation was included to test whether individuals' views on social hierarchy mediate relations between psychopathy and the Ingroup and Authority foundations. A measure of disgust sensitivity was included as a possible mediator of the Purity foundation. Finally, the Ethics Position Questionnaire was included as a supplementary measure to assess the general flexibility/rigidity of individuals' moral beliefs.

A final goal was to assess the role of two separate dimensions of psychopathy in the relationship between this construct and the moral foundations. Psychopathy has traditionally been conceptualized as having two factors (Hare, 1991), with Factor 1 including the personality and emotional features, and Factor 2 including the antisocial lifestyle/behavioral features. A central aim was to assess the relative contribution of each of these factors in predicting the five foundations of morality.

\section{METHOD}

\section{PARTICIPANTS}

Participants were 2,517 adult volunteers (39.1\% female, median age 35 years) on the yourmorals.org website who completed the Levenson Psychopathy Scale. Participants had previously registered on the site (reporting demographic information including age, sex, education, and a sevenpoint liberal-conservative measure of political identity) and self-selected to take one or more surveys based on the descriptions provided. Of the 2,517 participants who completed the Psychopathy Scale, 2,172 completed the Moral Foundations Questionnaire, 1,252 completed the Moral Foundations Sacredness Scale, 648 completed the Interpersonal Reactivity Index, 462 completed the Social Dominance Orientation Questionnaire, 1,343 completed the Disgust Scale, and 593 completed the Ethics Position Questionnaire. 
MATERIALS

Levenson's Self-Report Psychopathy Scale (LSRP). Psychopathy was assessed using the LSRP (Levenson, Kiehl, \& Fitzpatrick, 1995). The LSRP is a 26-item rating scale with two factors that were constructed to provide indices of the two factors of the Psychopathy Checklist-Revised (PCL-R; Hare, 1991), a semi-structured interview which is considered the gold standard for assessing psychopathy in forensic samples. Exploratory factory analysis revealed a two-factor structure that in fact mirrors the two factors of the PCL-R (Levenson et al., 1995). The Factor 1 subscale assesses the core personality traits of psychopathy, including manipulativeness, callousness, and lack of guilt or remorse; the Factor 2 subscale assesses features of the antisocial lifestyle, including impulsiveness, irresponsibility, and antisocial behavior. Items are rated on a 4-point Likert-type agree/disagree scale. The LSRP and its factor structure was initially validated in a sample of 487 undergraduates (Levenson et al., 1995) and was further validated by Lynam et al. (1999) in two studies of community participants. These two studies provided excellent evidence for the reliability and validity of the LSRP and strongly replicated the two-factor structure using confirmatory factor analyses and differential relations to personality dimensions. Predicted relations were observed between the LSRP and other self-report measures of delinquency and individuals scoring higher on the LSRP demonstrated task-related deficits similar to those observed in incarcerated psychopaths. A recent taxometric analysis of the LSRP found it to support the dimensional interpretation of psychopathy, consistent with findings on the PCL-R and other self-report measures (Walters, Brinkley, Magaletta, \& Diamond, 2008).

Moral Foundations Questionnaire. This scale consists of two 15-item parts. First, participants rated the moral relevance of foundation-specific concerns to their moral judgments using a 6-point scale anchored by "not at all relevant" and "extremely relevant" (e.g., When you decide whether something is right or wrong, to what extent do you consider whether or not someone was harmed?). In the second part, they indicated their agreement (on a 6-point agree/disagree scale) with more specific and contextualized moral statements such as "Loyalty to one's group is more important than one's individual concerns" (Ingroup) or "I would call some acts wrong on the grounds that they are unnatural" (Purity). Items and validity information about this scale can be found in Graham, Nosek, Haidt, Iyer, et al. (2009). Foundation means and reliabilities are shown in Table 1.

Moral Foundations Sacredness Scale. This 26-item scale indirectly measures how much an individual values each foundation of morality by asking how much money it would take to commit actions that violate each of the foundations, assuming no punishment or negative consequences. Participants rated a variety of behaviors that violate the moral foundations according to the following options: $\$ 0$ (I'd do it for free), $\$ 10, \$ 100, \$ 1,000$, $\$ 10,000, \$ 100,000$, A million dollars, or Never for any amount of money. Sample behaviors included "Get a blood transfusion of one pint of disease- 
TABLE 1. Descriptive Statistics for Study Measures and Subsamples

\begin{tabular}{|c|c|c|c|c|c|}
\hline & $N$ & Min & Max & Mean (SD) & Coefficient $\alpha$ \\
\hline Psychopathy & 2,517 & 26 & 94 & $46.17(10.53)$ & .870 \\
\hline Factor 1 & 2,517 & 16 & 62 & $26.60 \quad(7.54)$ & .868 \\
\hline Factor 2 & 2,517 & 10 & 38 & $19.57 \quad(4.92)$ & .716 \\
\hline \multicolumn{6}{|l|}{ Morality Foundations } \\
\hline Harm & 2,172 & 0 & 5.00 & $(.83)$ & .744 \\
\hline Fairness & 2,172 & 0 & 5.00 & $(.72)$ & .702 \\
\hline Ingroup & 2,172 & 0 & 4.88 & $(.89)$ & .760 \\
\hline Authority & 2,172 & 0 & 4.88 & $(.90)$ & .750 \\
\hline Purity & 2,172 & 0 & 5.00 & $1.81 \quad(1.11)$ & .851 \\
\hline \multicolumn{6}{|l|}{ Interpersonal Reactivity Index } \\
\hline Perspective Taking & 648 & 1.14 & 5.00 & $(.75)$ & .726 \\
\hline Fantasy & 648 & 1.14 & 5.00 & $(.82)$ & .717 \\
\hline Empathic Concern & 648 & 1.00 & 5.00 & 3.70 & .690 \\
\hline Personal Distress & 648 & 1.00 & 4.86 & 2.31 & .750 \\
\hline Social Dominance Orientation & 462 & 1.00 & 6.63 & $2.50 \quad(1.15)$ & .914 \\
\hline \multicolumn{6}{|l|}{ Disgust Scale } \\
\hline Core Disgust & 1,343 & 0 & 3.92 & $(.70)$ & .773 \\
\hline Animal Reminder & 1,343 & 0 & 4.00 & $(.82)$ & .788 \\
\hline Contamination & 1,343 & 0 & 3.80 & $(.76)$ & .559 \\
\hline Total & 1,343 & 0 & 3.80 & $(.63)$ & .864 \\
\hline \multicolumn{6}{|l|}{ Sacredness Scale } \\
\hline Harm & 1,252 & 1.60 & 8.00 & $6.14 \quad(1.23)$ & .669 \\
\hline Fairness & 1,252 & 1.00 & 8.00 & $6.66 \quad(1.20)$ & .704 \\
\hline Ingroup & 1,252 & 1.00 & 8.00 & $5.18 \quad(1.42)$ & .692 \\
\hline Authority & 1,252 & 1.00 & 8.00 & 4.15 (1.59) & .680 \\
\hline Purity & 1,252 & 1.00 & 8.00 & 5.77 (1.37) & .587 \\
\hline \multicolumn{6}{|l|}{ Ethics Positions Questionnaire } \\
\hline Idealism & 593 & 1.00 & 7.78 & $(.96)$ & .896 \\
\hline Relativism & 593 & 1.00 & 8.70 & $3.17 \quad(1.18)$ & .910 \\
\hline
\end{tabular}

free, compatible blood from a convicted child molester" (Purity violation) or "Burn your country's flag in private" (nobody else sees you; Ingroup violation). The more sacred a value is to an individual, the more money it would take to betray that value. Items for each foundation are averaged to yield a single sacredness score for that foundation. Items and validity information for this scale can be found in Graham, Haidt, and Nosek (2009), Study 3.

Interpersonal Reactivity Index (Empathy). This 28-item measure was used to measure individual differences in empathy (Davis, 1983). The scale covers four aspects of empathic responding: (1) Perspective-taking, or the tendency to adopt the psychological viewpoint of others, (2) Fantasy, or the tendency to transpose oneself imaginatively into the feelings and actions of fictitious characters in books, movies, and plays, (3) Empathic Concern, or feelings of sympathy and concern for unfortunate others, and (4) Personal Distress, or feelings of personal anxiety and unease in tense interpersonal settings.

Social Dominance Orientation Questionnaire. This 16-item questionnaire (Sidanius \& Pratto, 2001) was used to measure individual differences in group-based discrimination and domination, or a preference for social hierarchy versus equality in society (e.g., It's okay if some groups have more of a chance in life than others). This personality variable is also associated 
with a preference for aggression or meanness, punishment of low-status group members, and dominance of high-status groups (men, whites, upper classes, etc.).

Disgust Scale-Revised. This 25-item scale (Haidt, McCauley, \& Rozin, 1994; revised by Olatunji et al., 2007) was included to determine whether individual differences in sensitivity to disgust would mediate the potential relationship between psychopathy and the Purity foundation. Three subscales include: (1) Core disgust: the core of the emotion, which is about defending the mouth from contamination by dirty or inappropriate things like body excretions, vermin, and certain combinations of foods (e.g., It bothers me to hear someone clear a throat full of mucus), (2) Animalreminder disgust: things involving death, corpses, and violations of external boundaries of the body, such as amputations (e.g., It would bother me to be in a science class and to see a human hand preserved in a jar), and (3) Contamination disgust: defense of the whole body, not just the mouth, from contact with dirty or sleazy people (e.g., I never let any part of my body touch the toilet seat in public restrooms).

Ethics Positions Questionnaire. This 20-item questionnaire (Forsyth, 1980) was used to measure how people determine what is moral or immoral along two dimensions, idealism, and relativism. Idealism measures how willing a person is to consider committing an immoral act in the service of a greater good (e.g., A person should make certain that their actions never intentionally harm another even to a small degree). Relativism measures how much one subscribes to the idea that morality can vary depending upon situation and culture (e.g., There are no ethical principles that are so important that they should be a part of any code of ethics). This scale was included as a general assessment of rigidity of moral beliefs.

\section{RESULTS}

Means, standard deviations, and reliabilities of each scale are provided in Table 1 . Mean psychopathy scores did not differ between the subsamples that completed each of the other scales. Coefficient alphas for the psychopathy scale were .859 (total), .868 (Factor 1), and .716 (Factor 2); the correlation between the two factors was .401 .

Multiple regression was used to examine how well psychopathy scores predicted endorsement and sacredness of the five foundations (Table 2), as well as scores on the additional scales used to assess potential mediators and to provide supplementary information. Age, sex, education, and political identity were included as covariates in all regression analyses. Regressions were first conducted using total psychopathy scores. Because scores for the two psychopathy factors are highly correlated $(r=.401, p<$ .001 ), an additional set of regressions included both Factor 1 and Factor 2 of psychopathy to examine the relationship of each factor to the morality foundations while controlling for the other factor and demographic covariates. 
TABLE 2. Regression Analyses Predicting Study Measures

\begin{tabular}{|c|c|c|c|}
\hline & Total & Factor 1 & Factor 2 \\
\hline \multicolumn{4}{|l|}{ Morality Foundations $(n=2,172)$} \\
\hline Harm & $-.205^{* * *}$ & $-.288^{* * *}$ & .069 \\
\hline Fairness & $-.158^{* * *}$ & $-.214^{* * *}$ & .044 \\
\hline Ingroup & $.122^{* * *}$ & $.099 * * *$ & .045 \\
\hline Authority & .018 & .021 & -.001 \\
\hline Purity & $-.084 * *$ & $-.126^{* * *}$ & .038 \\
\hline \multicolumn{4}{|l|}{ Interpersonal Reactivity Index $(n=648)$} \\
\hline Perspective Taking & $-.333^{* * *}$ & $-.177^{* * *}$ & $-.240 * * *$ \\
\hline Fantasy & -.011 & -.084 & .083 \\
\hline Empathic Concern & $-.351 * * *$ & $-.419 * * *$ & .021 \\
\hline Personal Distress & .038 & -.045 & .039 \\
\hline Social Dominance Orientation $(n=462)$ & $.351^{* * *}$ & $.457^{* * *}$ & -.087 \\
\hline \multicolumn{4}{|l|}{ Disgust Scale $(n=1,343)$} \\
\hline Core Disgust & -.002 & $-.110^{*}$ & $.132^{* *}$ \\
\hline Animal Reminder & -.012 & -.086 & .089 \\
\hline Contamination & .014 & -.023 & .047 \\
\hline Total & -.003 & $-.101 *$ & $.120^{* *}$ \\
\hline \multicolumn{4}{|l|}{ Sacredness Scale $(n=1,252)$} \\
\hline Harm & $-.333^{* * *}$ & $-.375^{* * *}$ & .003 \\
\hline Fairness & $-.438 * * *$ & $-.449 * * *$ & -.048 \\
\hline Ingroup & $-.252^{* * *}$ & $-.194^{* * *}$ & $-.105^{* * *}$ \\
\hline Authority & $-.286 * * *$ & $-.207^{* * *}$ & $-.134 * * *$ \\
\hline Purity & $-.105^{* * *}$ & $-.125^{* * *}$ & .009 \\
\hline \multicolumn{4}{|l|}{ Ethics Position Questionnaire $(n=593)$} \\
\hline Idealism & $-.211^{* * *}$ & $-.290^{* * *}$ & .062 \\
\hline Relativism & $.214^{* * *}$ & $.202^{* * *}$ & .046 \\
\hline
\end{tabular}

Note. Summary of estimates from multiple regression models predicting moral foundations and other study variables from psychopathy scores, age, sex, education, and political views. Numbers indicate standardized beta $(\beta)$. Beta values in the left column are from multiple regressions including total psychopathy scores; values in the right two columns are from multiple regressions including both Factor 1 and Factor 2 psychopathy scores. Negative $\beta$ indicates lower scale ratings for individuals higher in psychopathy. ${ }^{*} p<.05 ;{ }^{* *} p<.01 ;{ }^{* * *} p<.001$

\section{MORAL FOUNDATIONS QUESTIONNAIRE.}

Total psychopathy scores most strongly predicted lower endorsement of the moral foundations of Harm and Fairness (Table 2). Of the two factors underlying psychopathy, Factor 1, which represents the affective and interpersonal features, was a stronger predictor than Factor 2. Psychopathy also predicted higher endorsement of the Ingroup foundation, in which Factor 1 was again a stronger predictor. Psychopathy was not a significant predictor of endorsement of the Authority foundations and demonstrated a weak negative relationship with the Purity foundation. Figure 1 (left) depicts the average foundation ratings across psychopathy scores.

Interpersonal Reactivity Index (Empathy). Regression results (Table 2) indicated that higher psychopathy scores were highly predictive of low scores on the Perspective Taking and Empathic Concern subscales of the Interpersonal Reactivity Index. These subscales were also positively correlated with the Harm (Empathic Concern: $r=.557, p<.001$; Perspective Taking: $r=.234, p<.001$ ) and Fairness foundations (Empathic Concern: 

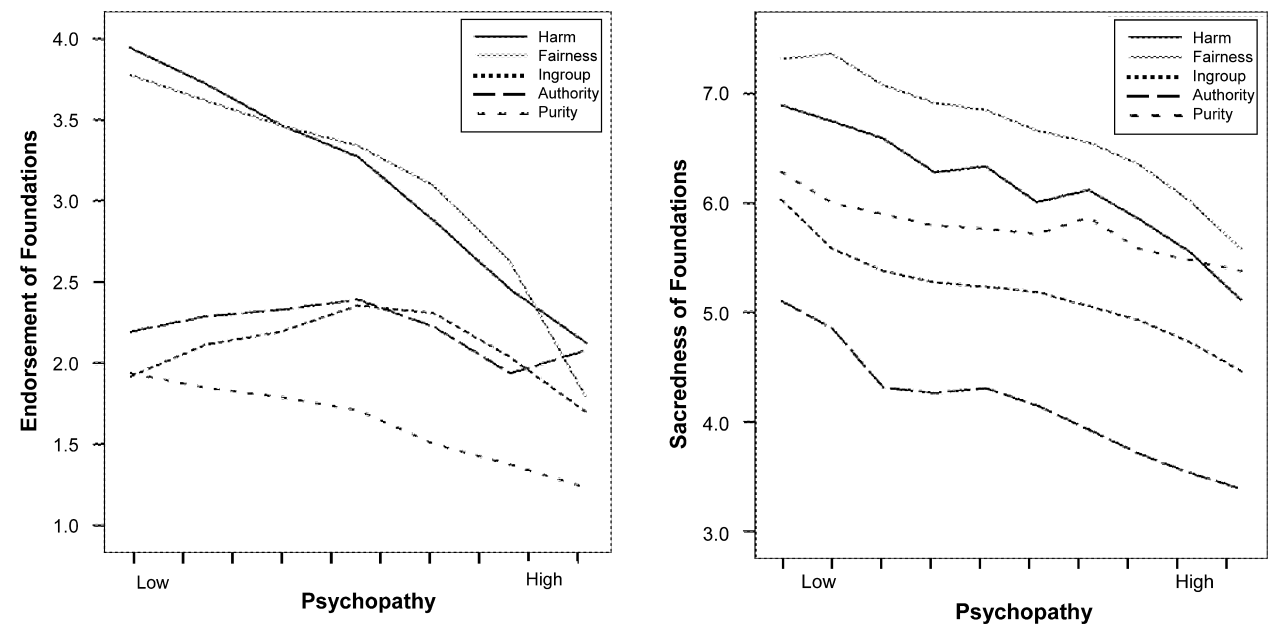

FIGURE 1. Endorsement (Moral Foundations Questionnaire) and sacredness (Sacredness Scale) of moral foundations across psychopathy scores. (Left) Psychopathy is primarily associated with reduced considerations of Harm and Fairness when making moral judgments. (Right) In all domains of morality, individuals scoring higher in psychopathy report that they would be willing to accept a lesser amount of money to commit an act violating moral principles. The range of psychopathy scores is divided into ten equal bins; data points represent the average of foundation scores for subjects within each bin.

$r=.446, p<.001$; Perspective Taking: $r=.166, p<.001$ ), indicating that they may serve as potential mediators of the relationship between psychopathy and the Harm and Fairness foundations (Baron \& Kenny, 1986). We tested the significance of Perspective Taking and Empathic Concern as potential mediators of this relationship (Sobel, 1982). Results revealed that Empathic Concern, but not Perspective Taking, mediated the relationship between psychopathy and the foundations of Harm (Sobel test statistic $=-13.98, p<.001)$ such that higher psychopathy scores predicted lower Emphatic Concern scores, which in turn predicted lower endorsement of the Harm foundation. A similar mediation was found for the Fairness foundation (Sobel test statistic $=-7.73, p<.001$ ). Figure 2(a) presents parameter estimates for both mediation models.

Social Dominance Orientation. The Social Dominance Orientation (SDO) scale was used to further explore the relationship between psychopathy and the Ingroup foundation (no relationship was found between Authority and psychopathy, so Authority was not included). Psychopathy was positively correlated with SDO $(r=.372, p<.001)$ and SDO was positively correlated with the Ingroup foundation $(r=.289, p<.001)$, making SDO a potential mediator of the relationship between psychopathy and the Ingroup foundation. A test of mediation revealed that SDO mediated the relationship between psychopathy and the Ingroup foundation (Sobel test statistic = $4.89, p<.001)$. Parameter estimates for the mediation model are presented in Figure 2(b). 

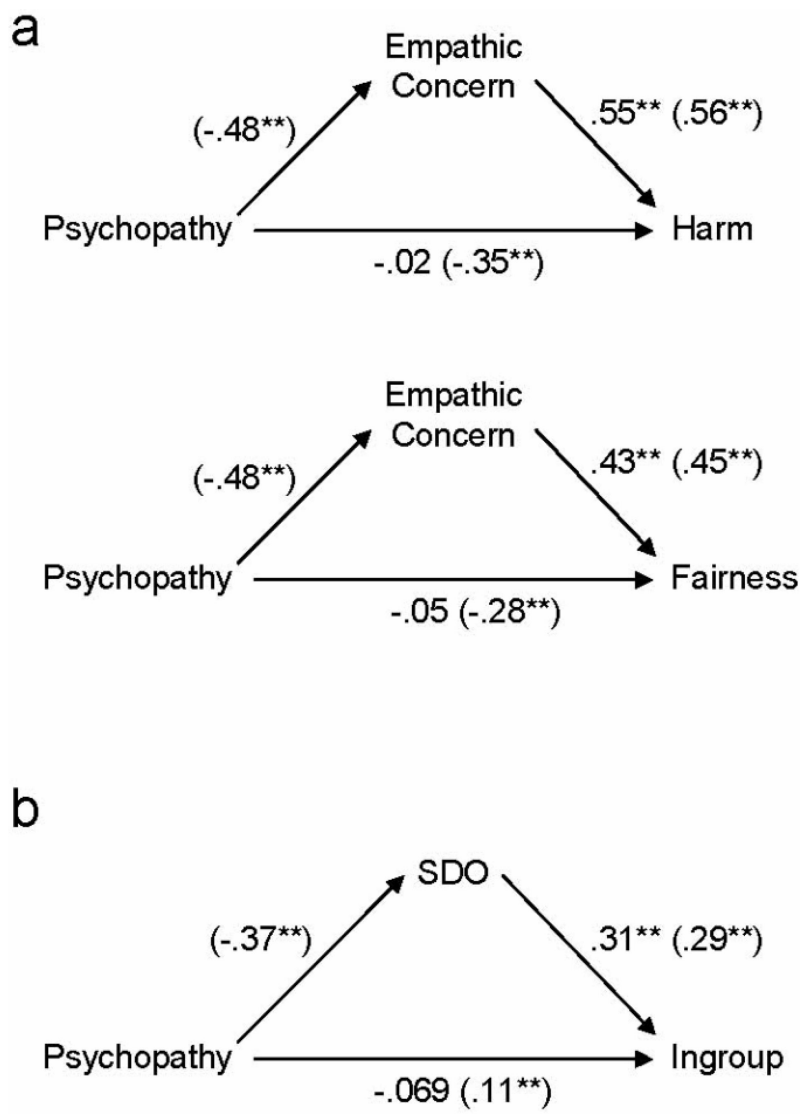

FIGURE 2. Results of mediation models. (a) Empathic Concern mediates the relationship between psychopathy and the foundations of Harm and Fairness. (b) Social Dominance Orientation mediates the relationship between psychopathy and the Ingroup foundation. In each model, the coefficients in parentheses represent the zero-order correlations between two variables, and the coefficients without parentheses represent the standardized regression coefficients $(\beta)$ from a simple linear regression model containing psychopathy and the mediator variable as predictors. ${ }^{*} p<.01$ and ${ }^{* *} p<.001$.

Disgust Scale. As reported above, psychopathy scores weakly predicted reduced endorsement of the Purity foundation. However, psychopathy was not a significant predictor of scores on the Disgust Scale or any of its subscales.

Sacredness Scale. Although psychopathy was primarily associated with reduced endorsement of Harm and Fairness foundations on the Moral Foundations Questionnaire, results of the Sacredness Scale showed that higher psychopathy predicted greater willingness to accept money to violate a moral principle on all five foundations (Table 2). Figure 1 (right) demonstrates the decrease in monetary amount ratings with increasing psychopathy scores. Factor 1 contributed relatively more variance in all foundations. 
Ethics Positions Questionnaire: Idealism versus Relativism. Psychopathy predicted less idealism and more relativism when determining what is moral (Table 2). In other words, more psychopathic individuals indicated they were more willing to violate moral principles in certain situations (e.g., to serve the greater good), and subscribed to the idea that morality can vary in different situations. Factor 1 accounted for more variance on both scales.

\section{DISCUSSION}

The present results suggest that the moral deficits observed in psychopathy are primarily concentrated in two domains-Harm and Fairness. When controlling for age, sex, education level, and politics, individuals scoring higher in psychopathy were significantly less likely to consider moral principles related to Harm and Fairness when making moral judgments in their daily lives. It was hypothesized that this finding may be due to deficits in psychopathic individuals' ability to experience certain elements of empathy, namely the ability to feel sympathy and concern for unfortunate others (Empathic Concern) and the ability to adopt the psychological perspective of others (Perspective Taking). Empathic Concern, but not Perspective Taking, was found to mediate the relationship between psychopathy and the Harm and Fairness foundations. This suggests that although psychopathy is associated with both Perspective Taking and Empathic Concern, reduced Empathic Concern may be primarily responsible for differences in moral judgments that involve considering whether others will be harmed or treated unfairly. Individuals lacking strong feelings of empathy may not find the wellbeing of others to be a salient concern, and thus may not be deterred from engaging in immoral behavior that causes harm to or exploits others. This result lends support for Blair's (2007) theory that psychopathic individuals may have impairments in learning to care about the welfare of others. The specificity of the deficits to the domains of Harm and Fairness may result from dysfunction of the amygdala and ventromedial prefrontal cortex, which are important in decision-making that involves concern for distress in others (Blair, 2007).

Individuals scoring higher in psychopathy demonstrated a small increase in endorsement of the Ingroup foundation, which involves concerns about loyalty and betrayal among ingroup members, and can also involve a lack of concern about outgroup members. More psychopathic individuals may exhibit increased endorsement of the Ingroup foundation for several reasons - they may exhibit more hostility toward members of other groups, less concern for members of other groups, or less tolerance for individuals who betray their own group. Consequently, they may prefer hierarchies among groups, especially as it allows their ingroup to dominate other groups. Psychopathy was indeed found to be highly associated with social dominance orientation, which was found to mediate the relationship between psychopathy and the Ingroup foundation. This suggests 
that ideas related to social dominance may disproportionately impact moral judgments regarding group dynamics in psychopathic individuals. Furthermore, they may be more likely to engage in behavior that reinforces social hierarchies, including using other groups to get ahead in life.

No relationship was observed between psychopathy and endorsement of the Authority foundation and only a weak relationship was observed with the Purity foundation, suggesting that when making moral decisions psychopathic individuals implement principles of these foundations at about the same rates as nonpsychopathic individuals. This is consistent with previous research involving conventional transgressions, in which psychopathic individuals did not demonstrate impairment in appropriately rating rule-based transgressions (Blair, 1995). There was also no relationship observed between the disgust and psychopathy. Some previous studies have found evidence of reduced experience of disgust in psychopaths (Forth, 1992; Kosson, Suchy, Mayer, \& Libby, 2002; Levenston et al., 2000) whereas others have not (Blair et al., 2001; Dolan \& Fullam, 2006). Further research is needed to clarify the relationship between psychopathy and disgust.

Interestingly, although psychopathy was primarily associated with low endorsement of the Harm and Fairness foundations, when an option of monetary reward was present, more psychopathic individuals indicated that they would accept a lesser amount of money to violate a moral principle regardless of the domain. This suggests that psychopathic individuals are more willing to disregard moral principles of any type for a nonmoral incentive such as money. This finding supports the idea that the impaired decision-making of psychopathic individuals may be partly a result of a motivational imbalance that involves enhanced sensitivity to reward (i.e., money) and reduced sensitivity to punishment (i.e., consequences of committing immoral acts; van Honk \& Schutter, 2006). Previous studies examining reward- and punishment-based responding in psychopaths have found that they have particular difficulty inhibiting punishable responses in conditions involving an alternative reward (Newman, 1998), and that psychopaths' behavioral disinhibition is most evident when there is a reward contingency for responding (Hiatt \& Newman, 2006). This is the first study to demonstrate how such effects may impact moral decision-making. It appears that for more psychopathic individuals, the rewarding aspect of receiving money outweighs the negative effects (e.g., emotions of guilt or remorse) associated with committing an immoral act. This finding is supported by results from the Ethics Position Questionnaire which suggest that more psychopathic individuals are generally less rigid in their beliefs about morality and are more willing to commit an immoral act in the face of competing alternatives.

Finally, the examination of the relative contributions of each psychopathy factor to the moral foundations revealed that Factor 1 was more strongly related to endorsement and sacredness of the Harm and Fairness foundations. Factor 1 describes many of the interpersonal and affective 
features of psychopathy, including a lack of empathy, that are likely important in making judgments about how others are treated. Factor 2 accounted for part of the variance in the sacredness of the Ingroup and Authority foundations, but not to the general endorsement of the foundations. This suggests that, at least for these two foundations, when an external reward comes into play, Factor 2 features of psychopathy begin to have more of an impact on moral judgment. Interestingly, Factor 2 features, such as impulsivity, irresponsibility, and stimulation seeking, appear to be more reward-based. It may be the case that individuals higher on Factor 2 are more motivated by the rewarding aspect of receiving money.

A primary limitation of the current study is the reliance on self-report data to assess psychopathy. Psychopathy can be a particularly difficult construct to measure because psychopaths are frequently dishonest. This is an issue that is problematic for both self-report and interview-based assessments. Online self-report measures have the advantage of being anonymous, but lack the insight that can be gained from lengthy interviews. Interview-based methods may suffer from the social pressure to please the interviewer, though this can be improved by including supplementary records. In the present study, the primary advantage of using a self-report measure was the ability to assess a very large sample of individuals. This allowed us to obtain a wide range of psychopathy scores from a community sample. As noted in the methods, the self-report measure used in the present study has been validated in large, community samples and factor analyses have indicated that the two factors obtained in the current sample mirror the two factors of the PCL-R, which is considered the goldstandard interview-based method for assessing psychopathy. Perhaps most important is the evidence that individuals scoring higher on the LSRP have demonstrated task-related deficits similar to those observed in incarcerated psychopaths. However, results of the present study should be extended in future studies with a more objective measure of psychopathy.

Taken together, results from the present study indicate that even within nonincarcerated populations, individual differences in psychopathic personality impact how moral judgments are made. Higher psychopathy scores predict a willingness to disregard moral guidelines primarily when they pertain to harm and fairness, indicating reduced consideration for how others are treated when making moral decisions. As hypothesized by Blair (2007), lack of empathic concern plays a key role in this process. In the presence of reward, psychopathy predicts a willingness to disregard moral guidelines in all domains, suggesting that rewards may be more salient than the negative emotions associated with committing immoral acts. The finding that alternative rewards play a significant role in moral decision-making of psychopathic individuals may have implications for the criminal justice system, which currently uses punishment rather than reward-based techniques for deterring individuals from committing immoral acts. 


\section{REFERENCES}

Aniskiewicz, A. S. (1979). Autonomic components of vicarious conditioning and psychopathy. Journal of Clinical Psychology, 35, 60-67.

Baron, R. M., \& Kenny, D. A. (1986). The moderator-mediator variable distinction on social psychological research: Conceptual, strategic, and statistical considerations. Journal of Personality and Social Psychology, 51, 11731182.

Benning, S. D., Patrick, C. J., \& Iacono, W. G. (2005). Psychopathy, startle blink modulation, and electrodermal reactivity in twin men. Psychophysiology, 42, 753-762.

Blair, R. J. (1995). A cognitive developmental approach to morality: Investigating the psychopath. Cognition, 57, 1-29.

Blair, R. J. (1999). Responsiveness to distress cues in children with psychopathic tendencies. Personality \& Individual Differences, 27, 135-145.

Blair, R. J. (2007). The amygdala and ventromedial prefrontal cortex in morality and psychopathy. Trends in Cognitive Sciences, 11, 387-392.

Blair, R. J., Colledge, E., Murray, L., \& Mitchell, D.G.V. (2001). A selective impairment in the processing of sad and fearful facial expressions in children with psychopathic tendencies. Journal of Abnormal Child Psychology, 29, 491-498.

Blair, R. J., Jones, L., Clark, F., \& Smith, M. (1997). The psychopathic individual: a lack of responsiveness to distress cues. Psychophysiology, 34, 192-198.

Blair, R. J., Mitchell, D.G.V., Richell, R. A., Kelly, S., Leonard, A., Newman, C., et al. (2002). Turning a deaf ear to fear: Impaired recognition of vocal affect in psychopathic individuals. Journal of Abnormal Psychology, 111, 682-686.

Cleckley, H. (1976). The mask of sanity (5th ed.). St. Louis, MO: Mosby.

Davis, M. H. (1983). Measuring individual differences in empathy: Evidence for a multidimensional approach. Journal of Personality and Social Psychology, 44, 113-126.

Dolan, M., \& Fullam, R. (2006). Face affect recognition deficits in personality- disordered offenders: Association with psychopathy. Psychological Medicine, 36, 1563-1569.

Edens, J. F., Marcus, D., Lilienfeld, S. O., \& Poythress, N. G. (2006). Psychopathic, not psychopath: Taxometric evidence for the dimensional structure of psychopathy. Journal of Abnormal Psychology, 115, 131-144.

Forsyth, D. R. (1980). A taxonomy of ethical ideologies. Journal of Personality and Social Psychology, 39, 175-184.

Forth, A. E. (1992). Emotion and psychopathy: A three-component analysis. Unpublished manuscript, Vancouver, Canada.

Graham, J., Nosek, B. A., \& Haidt, J. (2009). Exaggeration across the political divide. Manuscript submitted for publication.

Graham, J., Haidt, J., \& Nosek, B. A. (2009). Liberals and conservatives rely on different sets of moral foundations. Journal of Personality and Social Psychology, 96, 1029-1046.

Graham, J., Nosek, B. A., Haidt, J., Iyer, R., Koleva, S., \& Ditto, P. H. (2008). Broadening and mapping the moral domain: The development and validation of the moral foundations questionnaire. Manuscript submitted for publication.

Haidt, J., \& Graham, J. (2007). When morality opposes justice: Conservatives have moral intuitions that liberals may not recognize. Social Justice Research, 20, 98-116.

Haidt, J., McCauley, C., \& Rozin, P. (1994). Individual differences in sensitivity to disgust: A scal sampling seven domains of disgust elicitors. Personality \& Individual Differences, 16, 701-713.

Hare, R. D. (1991). Manual for the Hare psychopathy checklist-revised. Toronto: Multi-Health Systems.

Hare, R. D. (1999). Without conscience: The disturbing world of the psychopaths among us. New York: Guilford.

Hare, R. D. (2003). Hare psychopathy checklist-revised (PCL-R: 2nd ed.). Toronto: Multi-Health Systems, Inc.

Hiatt, K. D., \& Newman, J. P. (2006). Understanding psychopathy: The cognitive side. In C. J. Patrick (Ed.), Handbook of Psychopathy (pp. 334-352). New York: Guilford. 
Kohlberg, L. (1969). Stage and sequence: The cognitive-developmental approach to socialization. In D. A. Goslin (Ed.), Handbook of socialization theory and research. Chicago: Rand McNally.

Kosson, D. S., Suchy, Y., Mayer, A. R., \& Libby, J. (2002). Facial affect recognition in criminal psychopaths. Emotion, 2, 398-411.

Levenson, M. R., Kiehl, K. A., \& Fitzpatrick, C. M. (1995). Assessing psychopathic attributes in a noninstitutionalized population. Journal of Personality and Social Psychology, 68, 151-158.

Levenston, G. K., Patrick, C. J., Bradley, M. M., \& Lang, P. J. (2000). The psychopath as an observer: Emotion and attention in picture processing. Journal of Abnormal Psychology, 109, 373386.

Lilienfeld, S. O., \& Fowler, K. A. (2006). The self-report assessment of psychopathy: Problems, pitfalls, and promises. In C. J. Patrick (Ed.), Handbook of psychopathy (pp. 107-132). New York: Guilford.

Lynam, D. R., Whiteside, S., \& Jones, S. (1999). Self-reported psychopathy: A validation study. Journal of Personality Assessment, 73, 110-132.

Newman, J. P. (1998). Psychopathic behavior: An information processing perspective. In D. J. Cooke, A. E. Forth \& R. D. Hare (Eds.), Psychopathy: Theory, research and implications for soci- ety (pp. 81-104). Dordrecht, The Netherlands: Kluwer Academic.

Olatunji, B. O., Williams, N. L., Tolin, D. F., Sawchuck, C. N., Abramowitz, J. S., \& Lohr, J. M. (2007). The disgust scale: Item analysis, factor structure, and suggestions for refinement. Psychological Assessment.

Pritchard, J. (1835). A treatise on insanity and other disorders affecting the mind. London: Sherwood, Gilbert, and Piper.

Sobel, M. E. (1982). Asymptotic confidence intervals for indirect effects in structural equation models. In S. Leinhardt (Ed.), Sociological Methodology 1982 (pp. 290-312). Washington, DC: American Sociological Association.

Sidanius, J., \& Pratto, F. (2001). Social dominance: An intergroup theory of social hierarchy and oppression. Cambridge: Cambridge University Press.

Turiel, E. (1983). The development of social knowledge: Morality and convention. Cambridge: Cambridge University Press.

van Honk, J., \& Schutter, D.J.L.G. (2006). Unmasking feigned sanity: A neurobiological model of emotion processing in primary psychopathy. Cognitive Neuropsychiatry, 11, 285-306.

Walters, G. D., Brinkley, C. A., Magaletta, P. R., \& Diamond, P. M. (2008). Taxometric analysis of the Levenson self-report psychopathy scale. Journal of Personality Assessment, 90, 491-498. 